\title{
Regional Groundwater Evapotranspiration in Illinois
}

\author{
PAT J.-F. YEH \\ Institute of Industrial Science, University of Tokyo, Tokyo, Japan \\ J. S. FAMIGLIETTI \\ Department of Earth System Science, University of California, Irvine, Irvine, California
}

(Manuscript received 13 February 2008, in final form 8 October 2008)

\begin{abstract}
The role of shallow unconfined aquifers in supplying water for evapotranspiration (i.e., groundwater evaporation) is investigated in this paper. Recent results from regional land surface modeling have indicated that in shallow water table areas, a large portion of evapotranspiration comes directly from aquifers. However, little field evidence at the regional scale has been reported to support this finding. Using a comprehensive 19-yr (1984-2002) monthly hydrological dataset on soil moisture, water table depth, and streamflow in Illinois, regional recharge to and evaporation from groundwater are estimated by using soil water balance computation. The 19-yr mean groundwater recharge is estimated to be $244 \mathrm{~mm} \mathrm{yr}^{-1}(25 \%$ of precipitation), with uncertainty ranging from 202 to $278 \mathrm{~mm} \mathrm{yr}^{-1}$. During the summer, the upward capillary flux from the shallow aquifer helps to maintain a high rate of evapotranspiration. Groundwater evaporation (negative groundwater recharge) occurs during the period of July-September, with a total of $31.4 \mathrm{~mm}(10 \%$ of evapotranspiration). Analysis of the relative soil saturation at 11 depths from 0 to $2 \mathrm{~m}$ deep supports the dominance of groundwater evaporation across the water table in dry periods. The zero-flux plane separating the recharge zone from the evapotranspiration zone propagates downward from about 70- to $110-\mathrm{cm}$ depth during summer, reflecting the water supply from progressively lower layers for evapotranspiration. Despite its small magnitude, neglecting regional groundwater evaporation in shallow groundwater areas would result in underestimated root-zone soil moisture and hence evapotranspiration by as large as $20 \%$ in the dry summer seasons.
\end{abstract}

\section{Introduction}

In shallow water table areas, summer drying of rootzone soil moisture often results in an upward capillary flux from the underlying aquifer to sustain the strong evapotranspiration demand; this is referred to as groundwater evapotranspiration (hereafter groundwater evaporation). In wetland and playa areas, or in semiarid riparian environments, groundwater evaporation represents the major source of water for plants, particularly during drought periods (Schmidhalter et al. 1994; Dahm et al. 2003; Snyder and Williams 2000; Scott et al. 2006; Steinwand et al. 2006). Sophocleous and Perry (1985) found in Kansas that under shallow water table condi-

Corresponding author address: Pat J.-F. Yeh, Institute of Industrial Science, University of Tokyo, Be607, 4-6-1 Komaba, Meguro-ku, Tokyo 153-8505, Japan.

E-mail: patyeh@rainbow.iis.u-tokyo.ac.jp tions, $70 \%$ of springtime groundwater recharge was lost by evapotranspiration during the subsequent summer and fall.

Land surface parameterizations used in regional and global climate models traditionally lack groundwater representation, and therefore they do not allow for upward water flux drawn from below the bottom of a soil column. Their use is, consequently, limited to the deepwater table conditions where root-zone soil moisture and groundwater are essentially decoupled. At least for humid climates where the water table usually lies near the ground surface, regional climate directly interacts with groundwater through groundwater recharge and capillary rise. The regional groundwater modeling study by Levine and Salvucci (1999) found that the groundwatersupported evaporation reduces area-average groundwater recharge dramatically, and the reduction is highly dependent on the degree of water table coupling. Moreover, unlike the deep-water table conditions, the presence 
of the shallow water table would significantly alter the vertical soil moisture profile. Given that most land surface hydrological processes are highly dependent on soil moisture, the role of the shallow water table must be incorporated into land surface parameterizations used in climate models.

In recent years, several land surface parameterizations used for climate modeling (Famiglietti and Wood 1994; Stieglitz et al. 1997; Koster et al. 2000; Gutowski et al. 2002; York et al. 2002; Liang et al. 2003; Maxwell and Miller, 2005; Yeh and Eltahir 2005a,b; Cohen et al. 2006; Niu et al. 2007; Fan et al. 2007) have begun to explicitly represent groundwater processes as a result of increasing awareness of the importance of groundwater dynamics in global hydrological and climate systems (National Research Council 2004). Many of these modeling studies have consistently indicated that as much as 5\%-33\% of evapotranspiration comes directly from shallow aquifers. For example, York et al. (2002) found $5 \%-20 \%$ of evapotranspiration comes directly from shallow aquifers in Kansas. Cohen et al. (2006) found that groundwater contributes to $12 \%$ of the total evapotranspiration for a watershed in Minnesota. However, very few regional-scale $\left(>10^{3} \mathrm{~km}^{2}\right)$ field studies on groundwater evaporation can be found in literature to support these findings from land surface modeling studies.

\section{Literature review on groundwater evaporation}

Plants can extract moisture for transpiration during the growing season from deep soil layers or directly from a shallow water table. The proximity of the capillary fringe to the land surface allows plant roots to enter the saturated zone, while the root penetration is constrained by the anaerobic condition of the saturated zone (Miller and Eagleson 1982). Moreover, field evidence points to a close correlation between plant species and water table depth (Nichols 1993, 1994). One of the adaptive strategies of vegetation, particularly in water-limited ecosystems, is the development of deep roots and the use of hydraulic redistribution, which enables vegetation to make optimal use of resources available throughout the soil column (Oliveira et al. 2005; Amenu and Kumar 2008). Nepstad et al. (1994) estimated that half of the closed forests of Brazilian Amazonia depend on deep root systems to maintain green canopies during the dry season. Evergreen forests can maintain evapotranspiration during 5-month dry periods by absorbing water from the soil to depths of more than $8 \mathrm{~m}$. Maraux and Lafolie (1998) found in a maize-sorghum cropland of Nicaragua that during drought periods, the upward water flux into the root zone reached $2 \mathrm{~mm} \mathrm{day}^{-1}$, while the actual evapotranspiration was between 2 and $4 \mathrm{~mm}$ day $^{-1}$. Kleidon and Heimann (2000) also reported that water uptake from deep soils or groundwater contributes significantly to dry season transpiration in Amazonia. More recently, using the Moderate Resolution Imaging Spectroradiometer (MODIS) satellite data, Saleska et al. (2007) found increased greenness in the Amazon forests, even during the 2005 drought and concluded that trees are able to use deep roots and hydrologic redistribution to access groundwater during dry extremes.

Although still a relatively unexplored subject, historically the study of groundwater evaporation can be traced back to the 1920 s. From a laboratory soil column measurement of evaporation, Shaw and Smith (1927) found that evaporation in Yolo loam soil was significant when the water table is less than 3 m deep. Remson and Fox (1955) demonstrated that evapotranspiration from the shallow water table could be estimated by the suitable application of the Richards equation, with the depth to the water table being the most dominating factor that affects the ability of a particular soil to raise water to the ground surface. Gardner (1958) has shown analytically that the steady-state evaporation rate from a soil in the presence of a water table is dependent on the depth to the water table, the soil capillary conductivity, and the capillary potential at the ground surface. Starting from saturation conditions at the surface, as the dry-out proceeds, evaporation increases dramatically from at first a climate-controlled condition to being limited by the rate of water movement to the surface. Gardner and Fireman (1958) found a good agreement between the laboratory measurements of evaporation and the theoretical solution of Gardner (1958). They showed that for Chino clay and Pachappa sandy loam, the evaporation rate decreases significantly as the water table depth decreases from 1 to $3 \mathrm{~m}$ below the surface; however, upward movement and the evaporation of water is possible with the water table as deep as more than 10 m. Willis (1960) extended Gardner's (1958) analytical analysis to a two-layered soil system in shallowwater table conditions.

Other than the above laboratory studies, field investigations on groundwater evaporation using streamflow records have been reported at the local catchments by Tschinkel (1963), Daniel (1976), and Zecharias and Brutsaert (1988), who found that evaporation from groundwater was only $0.04,0.17$, and $0.05-0.3 \mathrm{~mm}_{\text {day }}{ }^{-1}$, respectively. By contrast, significant groundwater evaporation has been reported from the field studies in playa areas where the water table approaches the ground surface. Allison and Barnes (1985) estimated that groundwater evaporation in a dry salt lake site of South 
Australia varies between 90 and 230, with a mean of

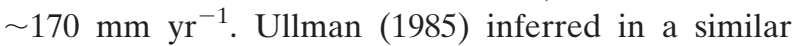
playa area in Australia that the groundwater evaporation lies between 9 and $28 \mathrm{~mm} \mathrm{yr}^{-1}$. Malek et al. (1990) estimated groundwater evaporation to be $\sim 229 \mathrm{~mm} \mathrm{yr}^{-1}$ from a moist playa in a closed desert basin in eastern Utah. Tyler et al. (1997) estimated that groundwater evaporation ranges between 88 and $104 \mathrm{~mm} \mathrm{yr}^{-1}$ at Owens Lake in California, where the annual precipitation is only $100-140 \mathrm{~mm}$.

Most of the aforementioned investigations have focused on laboratory or the local scale $\left(<1000 \mathrm{~km}^{2}\right)$ and only for relatively short study periods and data. The importance of groundwater evaporation on the regional scale ( 10 000-100 $000 \mathrm{~km}^{2}$ ), long-term hydrological cycle is unclear as a result of the complex spatiotemporal variability of the magnitude and direction of water fluxes across the water table (as reviewed above). In this study, a comprehensive 19-yr (1984-2002) hydrological dataset of Illinois $\left(\cong 10^{5} \mathrm{~km}^{2}\right)$ covering most of the hydrologic variables will be used to estimate groundwater evaporation. The long-term average water table depth in Illinois is about 2-4 m, and the magnitude of groundwater storage changes is as important as soil moisture storage changes at monthly time scales (Yeh et al. 1998; Yeh and Famiglietti 2008). The interaction between root-zone soil moisture and the shallow water table is investigated by the estimation of groundwater recharge. Of particular interest here is the significance of the upward water fluxes (i.e., negative groundwater recharge) from the water table to the root zone, and its role in maintaining a high summer evapotranspiration rate in Illinois.

\section{Data}

A comprehensive 19-yr (1984-2002) monthly dataset provided by the ISWS Illinois State Water Survey (ISWS) covering most of the hydrologic variables (e.g., precipitation, soil moisture, water table depth, streamflow, and evaporation estimate from water balance) will be used in this study for estimating groundwater recharge and groundwater evaporation. This long-term monthly dataset provides a unique opportunity to quantify the regional water balance for both unsaturated and saturated zones, and it has been used to investigate the regional hydroclimatology in Illinois (Yeh et al. 1998; Eltahir and Yeh 1999; Yeh and Famiglietti 2008). More details of the datasets on soil moisture and groundwater can be found in Changnon et al. (1988) and Hollinger and Isard (1994).

In the next section, the 1984-2002 monthly time series averaged from 129 precipitation stations, 16 soil moisture stations, 15 groundwater wells, and three stream- flow gauges at the outlets of the three largest river basins in Illinois are used to estimate groundwater recharge and groundwater evaporation. The sampling networks of soil moisture, groundwater depth, and streamflow are shown in Fig. 1. The occurrence of groundwater evaporation is defined here as when the estimated groundwater recharge is negative: the upward fluxes from the aquifer to the root-zone soil moisture are subsequently lost to the atmosphere by plant transpiration and soil evapotranspiration. The amount of groundwater evaporation is calculated by summation of the total negative groundwater recharge.

\section{Estimation of regional groundwater evaporation}

\section{a. Water balance equations}

Regional groundwater recharge is estimated here by soil water balance computation. The large-scale water balance equation for soil moisture can be written as

$$
n D \frac{d s}{d t}=P-E-R_{S}-P_{G},
$$

where $n$ is the soil porosity; $D$ is the active soil depth, which is taken as $2 \mathrm{~m}$ to be consistent with the soil moisture measurements in Illinois; $s$ is relative saturation; $P$ is precipitation; $E$ is evaporation; $R_{S}$ is surface runoff; and $P_{G}$ is percolation to the water table. Percolation across the 2-m soil depth is assumed to directly recharge the underlying water table because of the shallow groundwater conditions in Illinois. All the variables in Eq. (1) represent the regional-scale spatial averages.

The water balance equation for an unconfined aquifer can be written as

$$
S_{y} \frac{d H}{d t}=P_{G}-R_{G},
$$

where $S_{y}$ is the specific yield of the unconfined aquifer, $H$ is the groundwater level, and $R_{G}$ is groundwater runoff (base flow). Here, $S_{y}$ is estimated as 0.08 for the silt loam soil in Illinois following Yeh et al. (1998), and the derived groundwater storage change and total terrestrial water storage change were compared with the Gravity Recovery and Climate Experiment (GRACE) data with favorable results by Swenson et al. (2006) and Yeh et al. (2006).

Evaporation can be calculated by adding (1) and (2) together:

$$
E=P-\left(R+n D \frac{d s}{d t}+S_{y} \frac{d H}{d t}\right)
$$




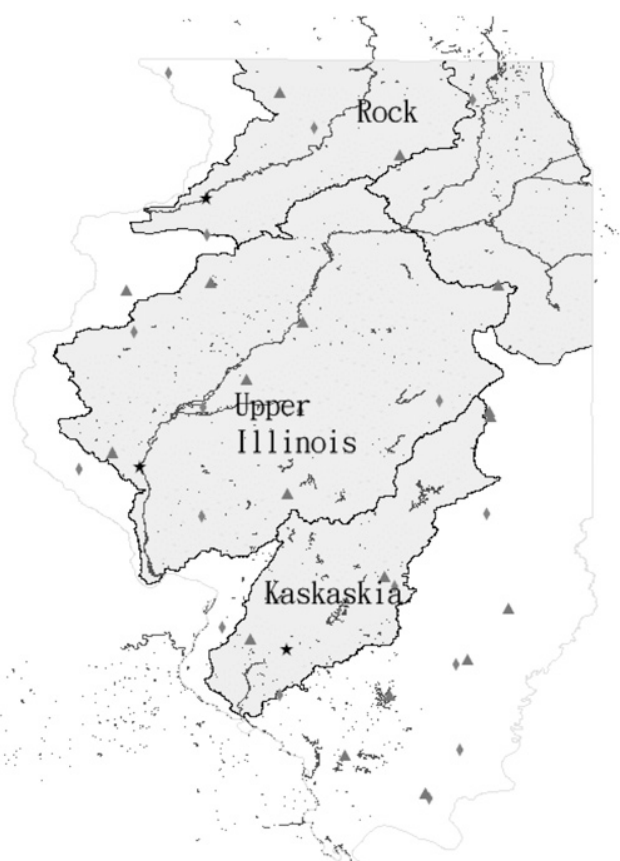

FIG. 1. The in situ networks of soil moisture (red triangles), water table depth (gray diamonds), and streamflow (black stars) measurements, and the basin boundary of the three largest river basins in Illinois. These three U.S. Geological Survey (USGS) stream gauges are selected as far downstream as possible, and their combined total drainage areas cover more than two-thirds of the area of Illinois.

where the total runoff is $R=R_{S}+R_{G}$. Using (3), Yeh et al. (1998) estimated the monthly regional evaporation and compared it to another independent estimate from the atmospheric water balance computation. The climatology of the two independent estimates agrees rather well with an error less than $10 \mathrm{~mm}^{\text {month }}{ }^{-1}$. Both evaporation estimates exceed observed precipitation by about 20-30 mm month ${ }^{-1}$ in the summer months June-August (see Fig. 5 of Yeh et al. 1998).

Figure 2 shows the 19-yr (1984-2002) average annual cycles of the soil water balance components in Illinois, including precipitation, evaporation [estimated from (3)], streamflow, and the storage changes in the soil moisture and groundwater. Annual average precipitation is $956 \mathrm{~mm} ; 70 \%$ of that water is returned to the atmosphere through evaporation, with runoff contributing the remaining $30 \%$. Although the storage changes in both soil moisture and groundwater are significant at the monthly time scale (with their magnitudes comparable to the runoff), their combined contributions to the annual water balance are small $\left(\sim 4 \mathrm{~mm} \mathrm{yr}^{-1}\right)$. Thus, the annual precipitation is partitioned into evaporation, surface runoff, and groundwater runoff. The amount of annual groundwater runoff is approximately equal to annual groundwater recharge, since the average groundwater storage integrates to zero at the annual time scale. Also plotted in Fig. 2 is evaporation estimated without the groundwater contribution [i.e., dropping the $S_{y} d H_{/} d t$ term in (3)]. As shown in Fig. 2, without the contribution from groundwater, the summer evaporation would not exceed the corresponding precipitation as already indicated from the atmospheric water balance analysis (Yeh et al. 1998). The difference between the two evaporation estimates from June to August is $70 \mathrm{~mm}$, which is equal to $\sim 20 \%$ of the total summer evaporation in Illinois. Therefore, the shallow aquifer is important in maintaining the high summer evaporation rate $(\sim 55 \%$ of the annual evaporation) in Illinois.

As observed in Fig. 2, evaporation exceeds precipitation by $\sim 30 \mathrm{~mm}$ month $^{-1}$ or larger in July and August, although soil water storage is at a minimum of a year. This suggests that surface runoff is negligible in the summer, and summer streamflow is largely sustained by groundwater. Although the decrease in soil water depletion reaches its peak in July, the significant decline in groundwater storages continues until September. As shown in Fig. 2, the decline in groundwater storage speeds up from May through the summer until it reaches its peak in August. The corresponding streamflow would rise if the decline in groundwater storage were to contribute streamflow. However, streamflow decreases during the period of May-September. Moreover, groundwater storage change in both August and September is larger than the corresponding streamflow, suggesting the existence of another mechanism at work other than base flow responsible for the depletion of groundwater storage during the two months. Yeh et al. (1998) reported that the regional hydrological cycle in Illinois is a closed system based on the close agreement found between the magnitude of long-term mean atmospheric water vapor convergence and streamflow. That is, any leakage across the bedrock of aquifers or lateral flow through the boundary is negligible. Therefore, the additional groundwater discharge mechanism would most likely be the groundwater supply to the overlying root-zone soil moisture to maintain the high summer evapotranspiration of about $130 \mathrm{~mm}$ month $^{-1}$, as shown in Fig. 2.

\section{b. Estimation of groundwater recharge and groundwater evaporation}

In (1) and (2), there are three unknowns-surface runoff $R_{S}$, groundwater runoff $R_{G}$, and groundwater recharge $P_{G}$-but only two equations. To estimate $P_{G}$, $R$ needs to be decomposed into $R_{S}$ and $R_{G}$. Multiple linear regression of monthly $R$ is used here with respect to its dependent variables (precipitation, soil moisture, and water table depth). Several regression equations 


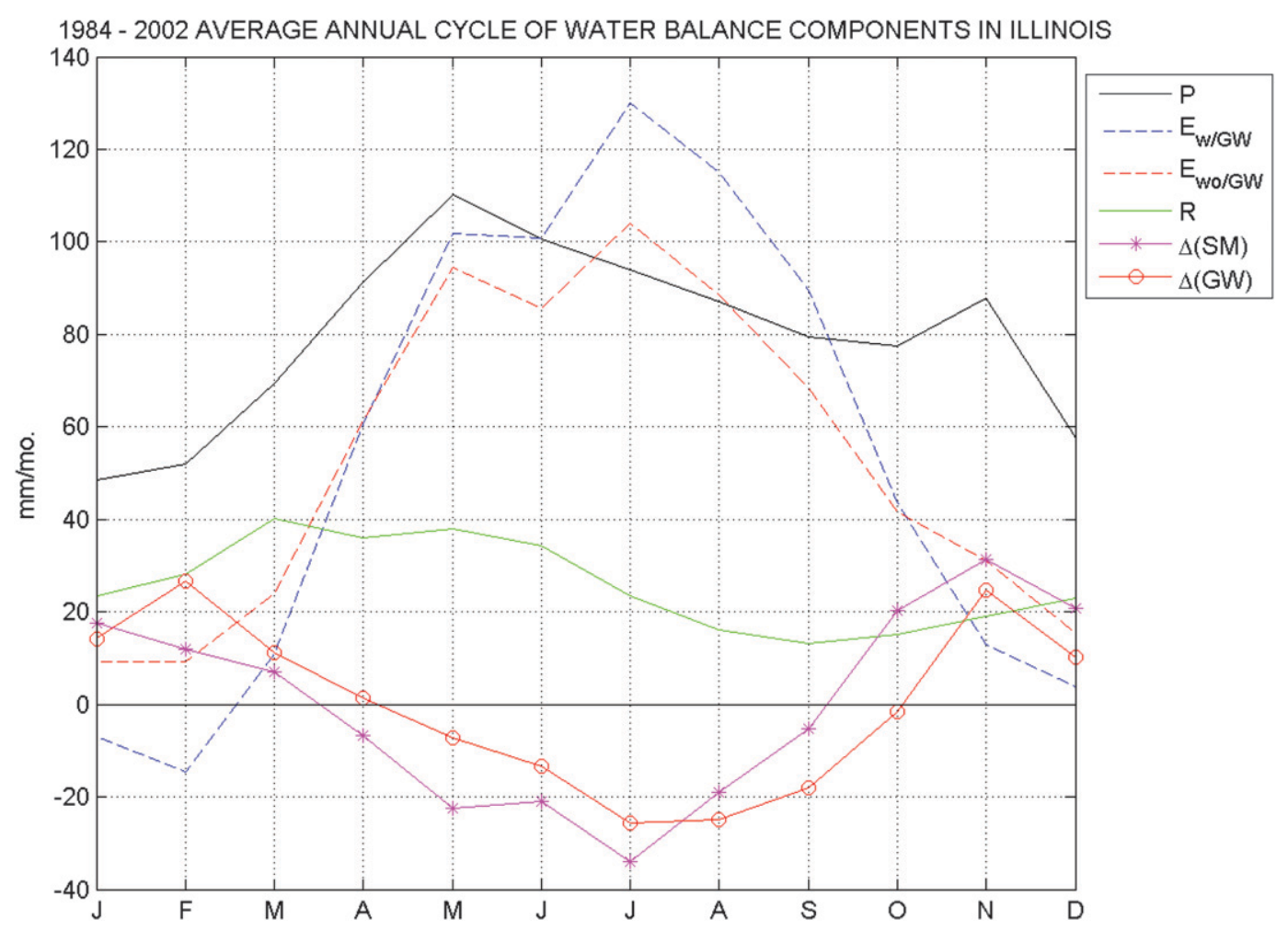

FIG. 2. The 19-yr (1984-2002) average annual cycles of soil water balance components in Illinois: $P$, precipitation; $E_{w / \mathrm{GW}}$, evaporation estimate from soil water balance computation; $E_{w o} / \mathrm{GW}$, evaporation estimate from soil water balance computation without incorporating groundwater contribution; $R$, streamflow; $\Delta(\mathrm{SM})$, soil moisture storage change; and $\Delta(\mathrm{GW})$, groundwater storage change.

with different forms and their corresponding coefficients of determination $\left(R^{2}\right)$ are given in Table 1. As shown, water table depth alone explains $63 \%$ of streamflow variance, while precipitation explains only $18 \%$. Therefore, it can be inferred that groundwater runoff dominates regional streamflow variability in Illinois. Moreover, water table depth and precipitation together explain two-thirds of the streamflow variance. After including the soil saturation, $R^{2}$ improves only marginally, which is a result of the high correlation between soil moisture and water table depth $(>0.7)$. It thus appears to be adequate to use precipitation and water table depth as the sole surrogate of surface runoff and groundwater runoff, respectively, in the streamflow regression.

To evaluate the uncertainty in the regression function forms, in the following subsection, the regression analysis will be conducted using two different expressions of groundwater runoff (baseflow) based on the observed water table depth. Additionally, the seasonality of surface and groundwater runoff will also be taken into account by monthly varying regression coefficients. The estimates using constant regression coefficients are presented in section $4 \mathrm{~b}(1)$, while estimates using monthly coefficients are in section $4 b(2)$.

\section{1) LINEAR REGRESSION WITH CONSTANT COEFFICIENTS}

Given the relatively short time scale of the lag between precipitation and surface runoff $(\leq 1$ month; Changnon et al. 1988), the following linear dependence can be assumed: $R_{S}=\alpha P$, where $\alpha$ is the surface runoff ratio. By contrast, the dependence of groundwater runoff

TABLE 1. Linear regression equations and the coefficients of determination for the monthly streamflow in Illinois for different combinations of dependent variables. Here, $P, R, s$, and $h$ are precipitation, streamflow, soil saturation degree, and water table depth (always positive), respectively.

\begin{tabular}{lc}
\hline \hline \multicolumn{1}{c}{ Regression equation } & $R^{2}$ \\
\hline$R=0.180 P+11.51$ & 0.184 \\
$R=189.11 s-118.55$ & 0.380 \\
$R=21.20 h+101.45$ & 0.628 \\
$R=0.11 P+180.16 s-120.27$ & 0.440 \\
$R=0.083 P+19.525 h+88.90$ & 0.664 \\
$R=39.38 s+17.97 h+54.25$ & 0.650 \\
$R=0.088 P+47.33 s+16.44 h+41.02$ & 0.670 \\
$R=680.62 \exp (-h)+2.62$ & 0.665 \\
$R=0.060 P+635.75 \exp (-h)-0.629$ & 0.683 \\
\hline
\end{tabular}


on water table depth is, in general, nonlinear based on the observations in Illinois (Eltahir and Yeh 1999, Fig. 12b). Groundwater runoff can thus be represented by the following exponential formula: $R_{G}=R_{0} \exp (-h)$, where $h$ is the water table depth (always positive) and $R_{0}$ is the maximum groundwater runoff when $h=0$. Thus,

$$
R=R_{S}+R_{G}=\alpha P+R_{0} \exp (-h)
$$

and the linear regression yields the following:

$$
R_{\mathrm{fit}}=\underset{(0.0334)}{0.06 P}+\underset{(66.66)}{635.75 \exp (-h)}-\underset{(3.047)}{0.63} \text {, }
$$

where $R$ and $P$ are in millimeters per month and $h$ is in meters. The numbers given in the parentheses below Eq. (5) denote the $95 \%$ of confidence interval for each fitting parameter in a least squares sense; that is, the range of $\alpha$ can be taken as being from 0.0266 to 0.0934 .

The comparison of fitted and observed streamflow is given in Fig. 3. As shown, the fitted streamflow follows the observation fairly well except for capturing some high flow peaks. The correlation coefficient between the observed and fitted streamflow is 0.83 , indicating that precipitation and groundwater depth together explains $\sim 70 \%$ of the streamflow variability. Here, $\alpha$ is estimated as 0.06 , which corresponds to 59 $\mathrm{mm} \mathrm{yr}^{-1}$ of surface runoff or $20 \%$ of the streamflow in Illinois.

By specifying $\alpha$ as $6 \%$ and recalling that $R=R_{S}+$ $R_{G}$ and $R_{S}=\alpha P$, groundwater recharge $P_{G}$ can be estimated from (2) or (1). Both equations should yield the same $P_{G}$, since the evaporation estimate in (3) is derived from the addition of first two equations. The 19842002 mean annual cycle of estimated groundwater recharge is plotted in Fig. 4a. The mean annual recharge is $244 \mathrm{~mm}$ ( $\sim 25 \%$ of precipitation), which is equal to the magnitude of groundwater runoff, since the average groundwater storage change integrates to zero during a year. Figure 4b plots the estimated 19-yr (1984-2002) monthly time series of groundwater recharge. The range of monthly recharge estimates varies from -40 (i.e., groundwater evaporation) to $150 \mathrm{~mm}$. The seasonal cycle of groundwater recharge (Fig. 4a) exhibits two peaks and one trough. Both peaks occur outside of the growing season. The first peak is in February-March and corresponds to the maximum of soil moisture and the groundwater level, while the trough in August corresponds to their minimum (see Fig. 3 in Yeh et al. 1998). The second peak of groundwater recharge occurs in November, when precipitation exhibits its second peak of the year. Significant groundwater recharge occurs in February-March, when the soil is nearly satu- rated such that most infiltration directly recharges the shallow water table, and in November, when precipitation minus evaporation is at the maximum of the year (see Fig. 2).

The groundwater recharge estimate is generally consistent with that reported in literature for humid regions. Stephens (1996) indicated that groundwater recharge varies between $20 \%$ and $50 \%$ of the mean annual precipitation in humid climates. Groundwater recharge generally occurs in the period from late fall through the following spring (Sophocleous and Perry 1985; Mau and Winter 1997), while little recharge takes place during summer months because of high evapotranspiration demand. Arnold et al. (2000, Fig. 11a) have estimated spatially distributed groundwater recharge in the upper Mississippi River basin. The range of their estimates in Illinois is consistent with that found in this study $(\sim 250$ $\mathrm{mm} \mathrm{yr}^{-1}$ ). Moreover, Arnold et al. (2000, Table 6) also estimated groundwater recharge in three small watersheds with contrasting hydroclimatology in Illinois to be 264, 99, and $202 \mathrm{~mm} \mathrm{yr}^{-1}$.

Groundwater evaporation (highlighted in yellow in Fig. 4) occurs during the period of July-September with a maximum of $\sim 15 \mathrm{~mm} \mathrm{mo}^{-1}$ in August and the total amount of $31.4 \mathrm{~mm}$, which equals $\sim 10 \%$ of total evapotranspiration (334 from July to September). During the summer, the upward groundwater flux replenishes the root-zone soil moisture, resulting in a steeper decline in groundwater storage than in soil water storage, as evidence in Fig. 2. The magnitude of groundwater evaporation is close to the upper end of the values $\left(0.05-0.3 \mathrm{~mm}\right.$ day $\left.^{-1}\right)$ reported by Tschinkel (1963), Daniel (1976), and Zecharias and Brutsaert (1988).

\section{2) LINEAR REGRESSION WITH MONTHLY COEFFICIENTS}

One potential limitation in the above analysis is that surface runoff generally depends on surface soil moisture status, hence $\alpha$ is supposed to exhibit strong seasonality. To examine the influence of seasonality, monthly values of $\alpha$ are estimated by applying the multiple linear regressions respectively to each month. This sensitivity test can serve as an evaluation of the uncertainty in estimated groundwater recharge and groundwater evaporation using constant regression coefficients. Another deficiency in the above analysis is due to the potential delay between aquifer storage and groundwater runoff. Here, the aquifer delay mechanism can be simply accounted for by parameterizing groundwater runoff following Eltahir and Yeh [(1999), Eq. (7)]: 
(a)
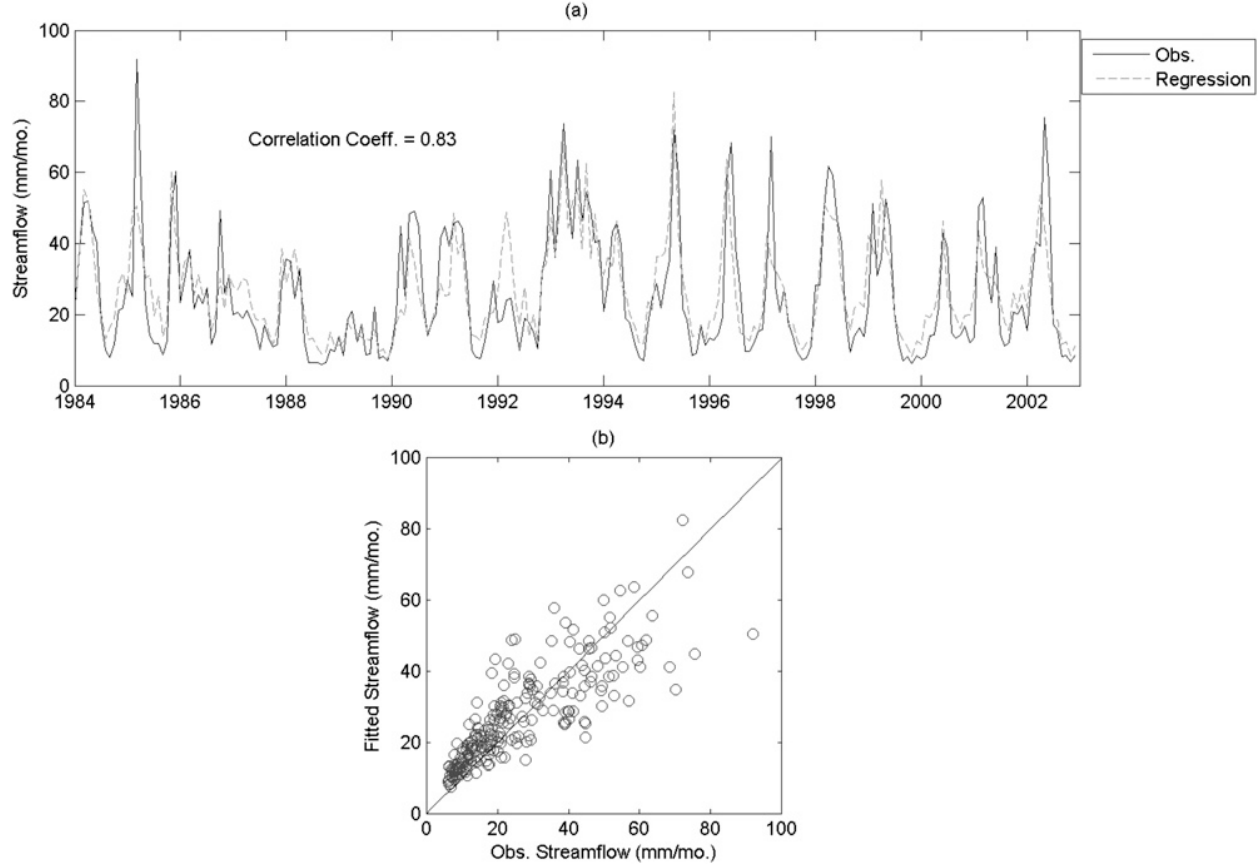

FIG. 3. The 1984-2002 (a) time series and (b) scatterplot of observed monthly streamflow vs the fitted streamflow in Illinois by using the multiple linear regressions.

$$
R_{i}=\alpha_{i} P_{i}+\frac{S_{y}\left(h_{o i}-h_{i}\right)}{T_{i}} \quad i=1,2,3 \ldots \ldots .11,12,
$$

where $S_{y}$ is the specific yield representing the unconfined water equivalence, $h_{0}$ (always positive) is a con- stant reference level of stream, and $T$ is the mean residence time of regional aquifer system. The value of $S_{y}$ is taken as 0.08 for the silt loam soils (the dominate soil texture in Illinois; see Hollinger and Isard 1994, their Table 2) following previous studies (Yeh et al. 1998;
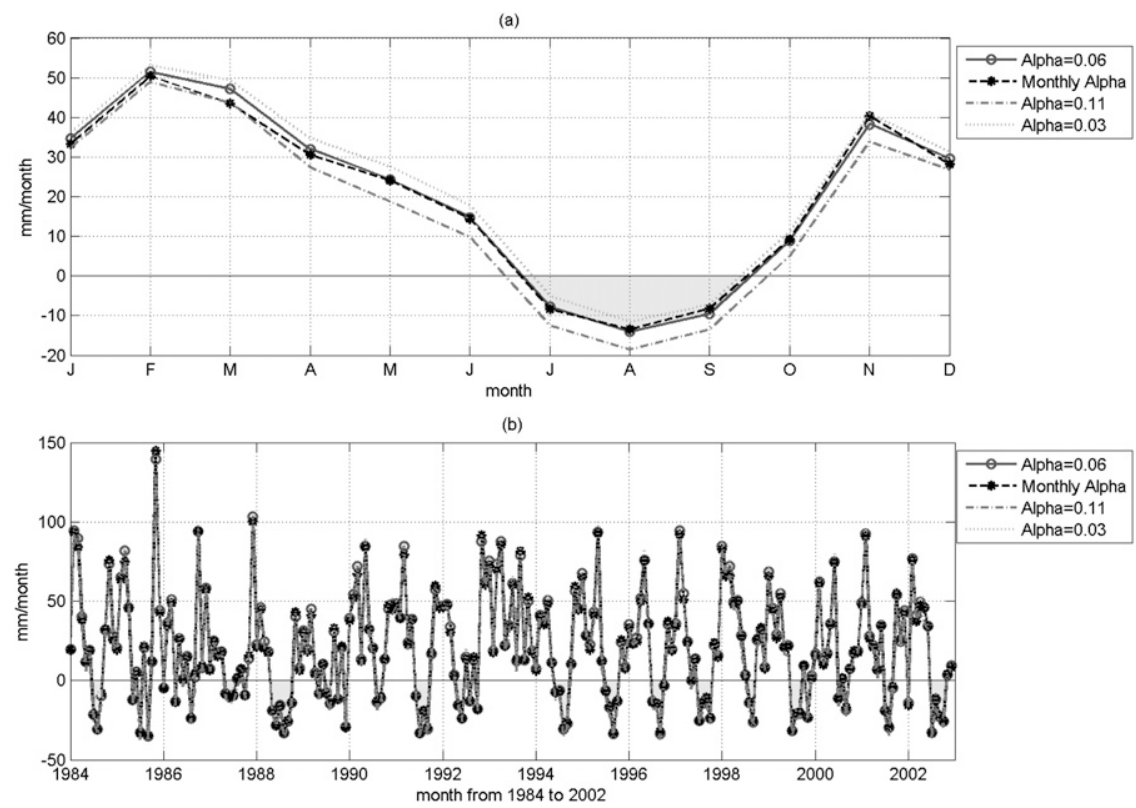

FIG. 4. The 1984-2002 (a) average annual cycle and (b) monthly time series of the estimated groundwater recharge for constant $\alpha=0.03,0.06$, and 0.11 , and monthly variant $\alpha$. (Highlighted in yellow is groundwater evaporation, i.e., negative groundwater recharge). 
TABLE 2. The 19-yr (1984-2002) average monthly soil water balance components and monthly regression coefficients using Eq. (6).

\begin{tabular}{|c|c|c|c|c|c|c|c|c|c|}
\hline & $P$ & $R$ & $h$ & $\alpha$ & $T_{G}$ & $h_{0}$ & $R_{S}$ & $R_{G}$ & $P_{G}$ \\
\hline (unit) & $\mathrm{mm}$ & $\mathrm{mm}$ & $\mathrm{m}$ & $\%$ & months & $\mathrm{m}$ & $\mathrm{mm}$ & $\mathrm{mm}$ & $\mathrm{mm}$ \\
\hline Jan & 48.42 & 23.39 & 3.47 & 9.00 & 4.73 & 4.59 & 3.27 & 20.12 & 34.31 \\
\hline Feb & 52.08 & 28.13 & 3.15 & 8.27 & 4.50 & 4.49 & 3.52 & 24.61 & 51.16 \\
\hline Mar & 69.41 & 40.06 & 3.02 & 11.28 & 2.38 & 3.98 & 4.69 & 35.37 & 46.68 \\
\hline Apr & 91.32 & 36.02 & 3.03 & 7.51 & 3.32 & 4.24 & 6.17 & 29.84 & 31.27 \\
\hline May & 110.17 & 38.05 & 3.13 & 6.24 & 2.65 & 4.16 & 7.45 & 30.60 & 23.48 \\
\hline Jun & 100.58 & 34.18 & 3.36 & 6.37 & 2.91 & 4.37 & 6.80 & 27.38 & 14.04 \\
\hline Jul & 94.06 & 23.51 & 3.72 & 6.55 & 3.25 & 4.43 & 6.36 & 17.15 & -8.55 \\
\hline Aug & 87.11 & 16.10 & 4.03 & 5.24 & 5.11 & 4.77 & 5.89 & 10.21 & -14.75 \\
\hline Sep & 79.44 & 13.20 & 4.19 & 4.38 & 5.31 & 4.83 & 5.37 & 7.83 & -10.11 \\
\hline Oct & 77.39 & 15.13 & 4.18 & 5.49 & 4.61 & 4.81 & 5.23 & 9.90 & 8.28 \\
\hline Nov & 87.89 & 18.96 & 3.85 & 3.60 & 6.16 & 5.07 & 5.94 & 13.02 & 37.61 \\
\hline Dec & 57.61 & 22.94 & 3.69 & 8.52 & 5.11 & 4.84 & 3.89 & 19.04 & 29.15 \\
\hline Avg & 79.62 & 25.80 & 3.57 & 6.76 & 4.37 & 4.69 & 5.38 & 20.42 & 20.21 \\
\hline Annual total & 955.5 & 309.7 & - & - & - & - & 64.6 & 245.1 & 242.6 \\
\hline
\end{tabular}

Rodell and Famiglietti 2001; Yeh et al. 2006). This value of $S_{y}$ has been used (Yeh et al. 1998; Yeh and Famiglietti 2008) to estimate regional soil and groundwater balance.

By applying linear regressions to (6), the monthly surface runoff coefficient $\left(\alpha_{i}\right)$ and the residence time $\left(T_{i}\right)$ are determined for each of the 12 months (Table 2). The comparison of observed and regressed streamflow is plotted in Fig. 5 for each month, where a remarkable agreement can be observed, as evidenced by a high correlation coefficient of 0.84 , slightly higher than the case of using constant regression coefficients.

From Table 2, the mean value of monthly $\alpha_{i}$ is $6.76 \%$, which is close to the $6 \%$ estimated from the constant coefficient regression. Here, $\alpha_{i}$ is assumed to repeat the same seasonal cycle for each year, and the resulting groundwater recharge and the surface and groundwater runoff are given in Table 2. As shown, $\alpha_{i}$ exhibits a clear seasonal cycle with a maximum (minimum) in March (November). The residence time of regional aquifer $T_{i}$ also clearly shows a seasonal cycle with the mean value of 4.4 months; $T_{i}$ is largest (smallest) in November (March), an exactly opposite correspondence with $\alpha_{i}$. In addition, $h_{0_{i}}$ represents a regression residual constant and carries less significant physical meaning.

\section{c. Uncertainty of groundwater recharge and evaporation estimates}

The estimated monthly $\alpha$ has an annual range from $3.6 \%$ to $11.3 \%$, which is close to the confidence interval of $\alpha$ in Eq. (5), using the constant regression coefficients. By inserting the monthly $\alpha_{i}$ and $\alpha=0.03$ and 0.11 into (1) or (2), the estimated groundwater recharges are compared in Fig. 4a. The range of $\alpha(0.03-0.11)$ corresponds to the surface runoff of $\sim 10 \%-33 \%$ of stream- flow. The 19-yr mean groundwater recharge ranges from $202(\alpha=0.11)$ and 243 (monthly $\alpha)$ to $278 \mathrm{~mm}(\alpha=0.03)$. As shown in Fig. 4a, the uncertainty in $\alpha$ has only a secondary influence on the estimated recharge, primarily because of the small magnitude of surface runoff [ $\sim 25 \%$ of streamflow as estimated by Eltahir and Yeh $(1999$, p. 1209)] in the overall water balance in Illinois (see Table 2).

The sensitivity of $\alpha$ on the estimated groundwater evaporation is also evaluated. The mean groundwater evaporation is found to be $23.6,31.4$, and $44.5 \mathrm{~mm} \mathrm{yr}^{-1}$, for $\alpha=0.03,0.06$, and 0.11 , respectively. Moreover, the number of months for the occurrence of groundwater evaporation (negative recharge) during the 19-yr (228 months) period is 66,66 , and 74 , respectively. Consistent among different estimates is that groundwater evaporation occurred during six consecutive months (May-October) for the anomalously dry 1988, while no groundwater evaporation occurred for the anomalously wet 1993 . If other terms in (1) remained unchanged, a larger surface runoff than $6 \%$ has to be balanced by a smaller recharge, resulting in larger groundwater evaporation. Therefore, $31.4 \mathrm{~mm} \mathrm{yr}^{-1}$ ( $\sim 10 \%$ of evapotranspiration), as estimated in this study, is considered as conservative for groundwater evaporation in Illinois.

\section{d. Correlation between precipitation and groundwater recharge}

The 19-yr annual precipitation is plotted against annual groundwater recharge and groundwater evaporation in Figs. 6a and 6b, respectively. For each year, annual groundwater evaporation is calculated by summation of all the negative monthly groundwater recharge. As shown in the figures, annual recharge is strongly 

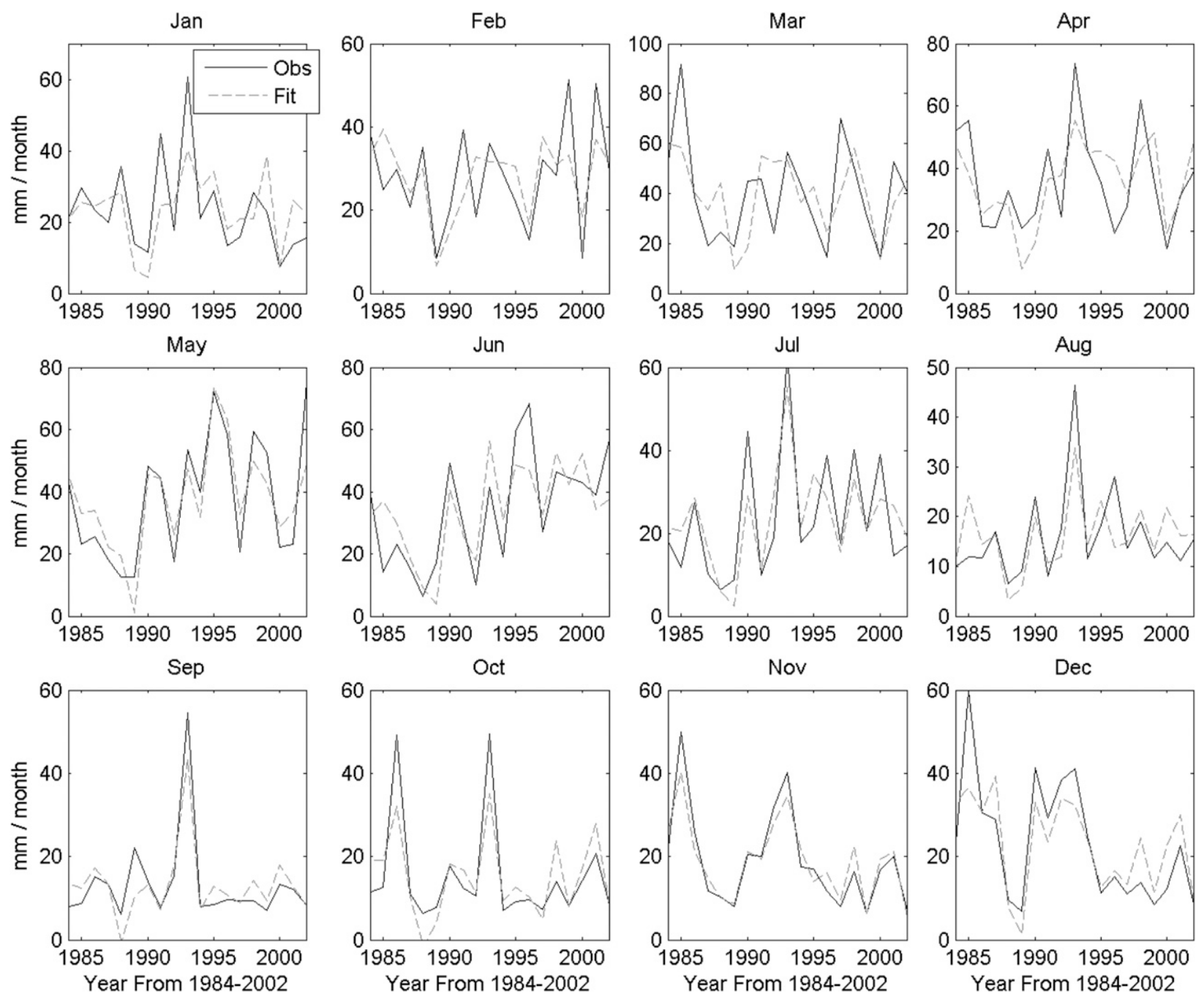

FIG. 5. The 1984-2002 observed monthly streamflow vs the fitted streamflow in each of 12 months by using the variant coefficient linear regression.

proportional to annual precipitation $(R=0.94)$. Although precipitation ranges between 700 and 1300 $\mathrm{mm} \mathrm{yr}^{-1}$ during 1984-2002, groundwater recharge can vary as large as from zero (in the driest 1988) to $600 \mathrm{~mm} \mathrm{yr}^{-1}(\sim 50 \%$ of precipitation in the wettest 1993). Conversely, groundwater evaporation shows a negative correlation $(R=-0.65)$ to precipitation with its range from zero (in 1993) to $140 \mathrm{~mm} \mathrm{yr}^{-1}$ ( $\sim 20 \%$ of evaporation in 1988).

Figure 7 presents a scatter similar to Fig. 6, but at the monthly time scales, and this plot is also stratified on a seasonal basis. As seen, monthly groundwater recharge is-in general-proportional to precipitation but with a low correlation $(R=0.39)$. Because of the nearly saturated soil water conditions during winter, substantial amounts of recharge $\left(>50 \mathrm{~mm}\right.$ month $\left.^{-1}\right)$ still take place, despite that winter precipitation is lowest among all four seasons (Fig. 2). However, significant recharge $\left(>50 \mathrm{~mm}\right.$ month $^{-1}$ ) can be found in summer and fall only when precipitation is $>100 \mathrm{~mm} \mathrm{month}^{-1}$ (Figs. 7c and $7 d$ ). This seasonal difference underscores the importance of soil moisture in regulating groundwater recharge. On the other hand, groundwater evaporation occurs during summer whenever precipitation falls below $100 \mathrm{~mm}$ month $^{-1}$. The relatively high correlation $(R=\sim 0.7)$ between precipitation and groundwater recharge during summer and fall indicates that most of the rainwater infiltrates into the soils during the period. Therefore, we concluded that the magnitude of groundwater evaporation is proportional to the deficit in soil water availability in the summer of Illinois, and the probability of groundwater evaporation occurrence is virtually nil if precipitation is greater than $>100 \mathrm{~mm} \mathrm{month}^{-1}$, irrespective of the season. 
(a)

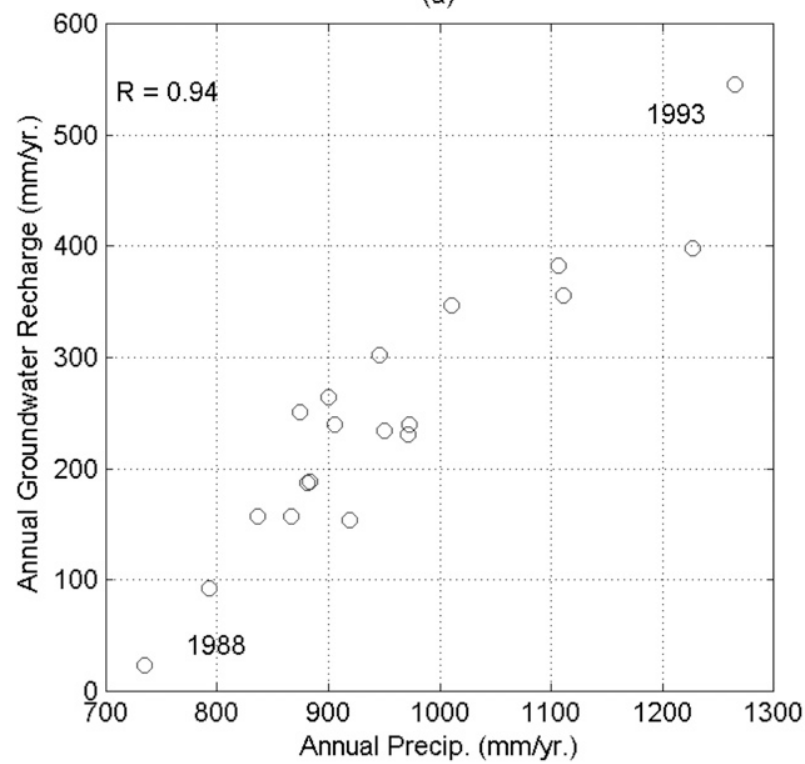

(b)

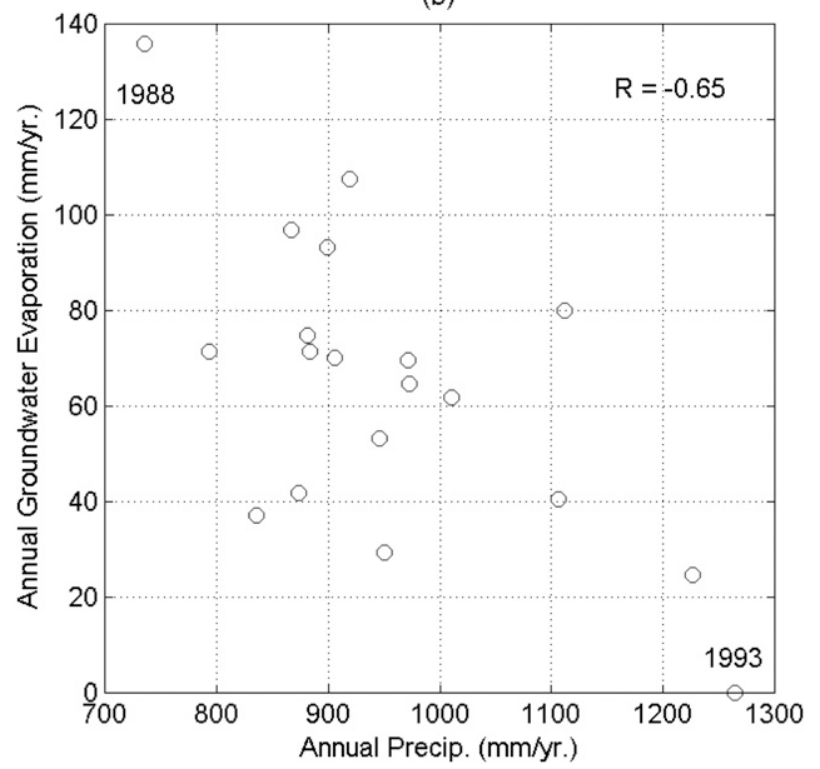

FIG. 6. Scatterplot of 1984-2002 mean annual precipitation vs mean annual (a) groundwater recharge and (b) groundwater evaporation. Annual groundwater evaporation is calculated by summing all the negative values of groundwater recharge for each year.

\section{Evidence of regional groundwater evaporation}

The 19-yr (1984-2002) monthly soil moisture dataset, collected by the ISWS at 11 depths within the upper $2 \mathrm{~m}$ of soils, provides a chance to characterize vertical soil moisture profiles and soil water movement through the $2 \mathrm{~m}$ deep soil layers. The relative soil saturation at 11 depths is plotted in Fig. 8 on a monthly basis. As shown in this figure, no apparent storage change can be ob- served in the lower $1 \mathrm{~m}$ of the soil; soil relative saturation remains at above 0.8 (close to the field capacity) throughout the year. Substantial seasonal variability, however, occurs in the upper four soil layers (i.e., 0-10, $10-30,30-50$, and $50-70 \mathrm{~cm}$ hereafter refers to layers $1-4)$. The maximum relative saturations in layers 1-4 occurs in four consecutive months from January to April, indicating a moisture flux within these layers propagates downward to recharge the underlying layers. Conversely, the drying of these upper layers begins from April until August, corresponding to a decrease in the surface soil saturation from 0.7 to 0.4 . The minimum relative saturation of these four layers occurs simultaneously in August, when the upward soil moisture gradient is at a maximum as a consequence of the strong evapotranspiration demand in summer.

Vertical soil water movement through soil layers is analyzed next. Since the driving force governing soil water movement is the hydraulic gradient, the measured relative saturation is transformed into capillary (matric) potential using the empirical soil water retention relationship of Clapp and Hornberger (1978): $\psi=\psi_{S} / s^{B}$, where $s$ is the soil saturation; $\psi_{S}$ is the capillary potential $(\psi)$ at saturation; and $B$ is an empirical parameter characterizing the soil type. The major U.S. Department of Agriculture (USDA) soil texture class in Illinois is silt loam. According to Hollinger and Isard (1994, their Table 2), the soil textures in 15 of 16 soil moisture measurement sites are predominately silty loam. In the following analysis, the vertical profile of soil texture for all the sites is assumed to be uniform as a result of the unavailability of data on the vertical variability of soil texture. Following Clapp and Hornberger (1978, their Table 2), the parameter $B$ and $\psi_{S}$ are taken as 5.3 and $786 \mathrm{~mm}$, respectively, for silt loam soil. Given the derived soil water potential, the direction of vertical soil water fluxes across each interface of the soil layers can be determined by calculating the hydraulic gradient between the adjacent layers. To characterize the average profile of vertical soil water fluxes, we avoid direct spatial averaging over the 16 soil moisture stations as a result of the nonlinearity of the unsaturated flow process. Instead, the probability for the occurrence of upward water fluxes in the 19-yr period at each soil layer interface for each month is computed for each station. For each month, the sample number is $16 \times 19=304$ for each soil layer interface, which is considered to be sufficiently large for the characterization of the representative vertical soil water movement in Illinois.

The result is presented in the contour plot of Fig. 9. As shown, the highest probability $(>0.8)$ for the occurrence of upward flux is found to be at the root-zone depth of about $30-50 \mathrm{~cm}$. This is indicative of the upward 
(b) Spring (MAM)

(a) All Months

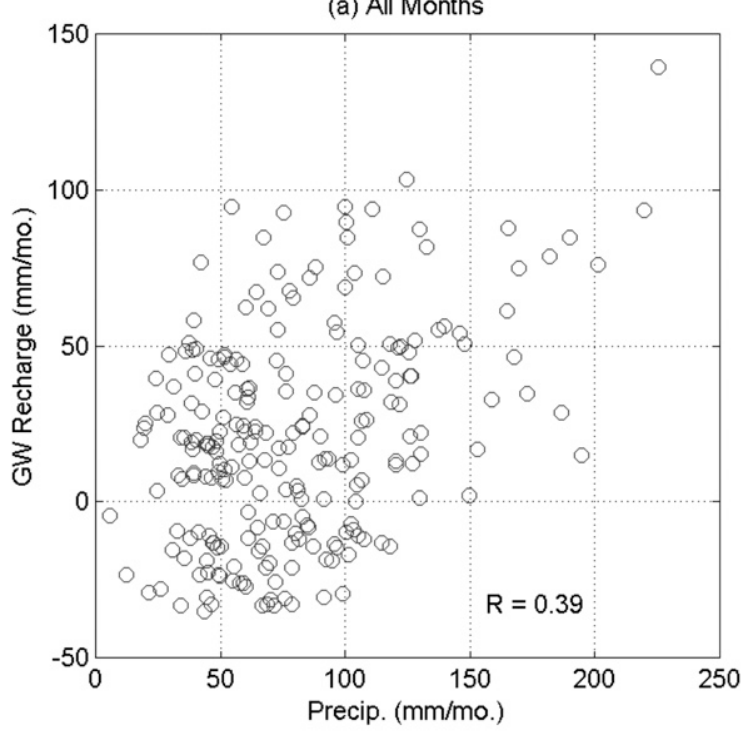

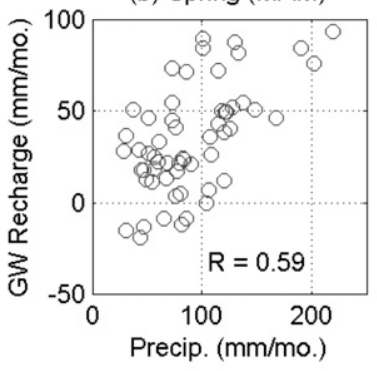

(d) Autumn (SON)

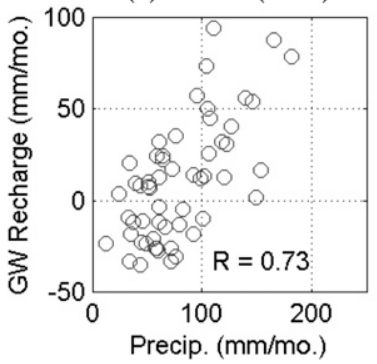

(c) Summer (JJA)

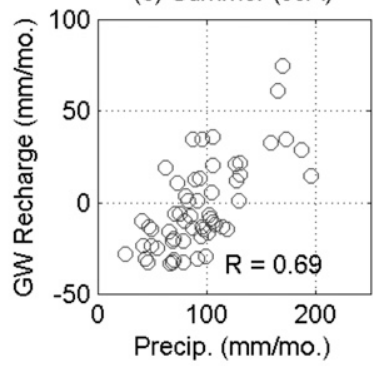

(e) Winter (NDJ)

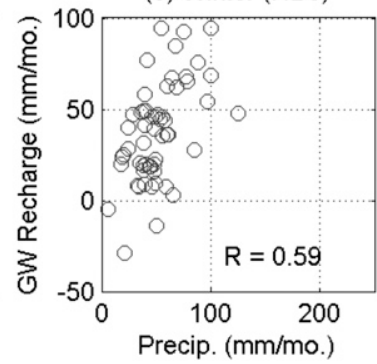

FIG. 7. (a) Same as Fig. 6a, but for the monthly time scale. The scatterplot is stratified into four seasons [(b) spring = MarchMay; (c) summer = June-August; (d) fall = September-November; (e) winter = December-February].

(a) Spring

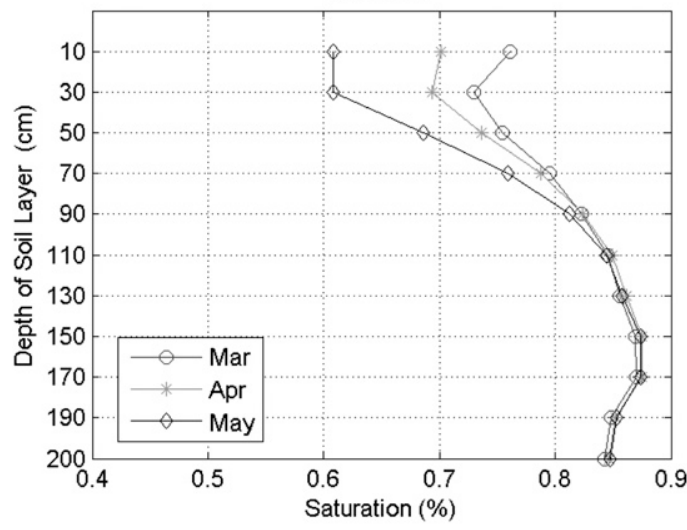

(c) Autumn

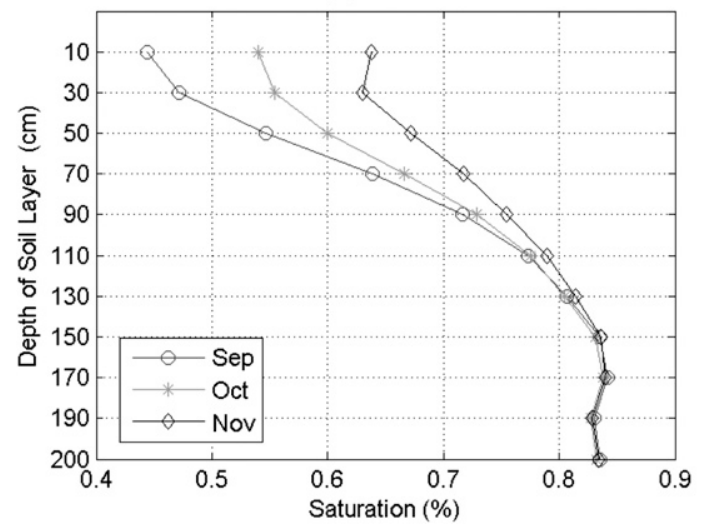

(b) Summer

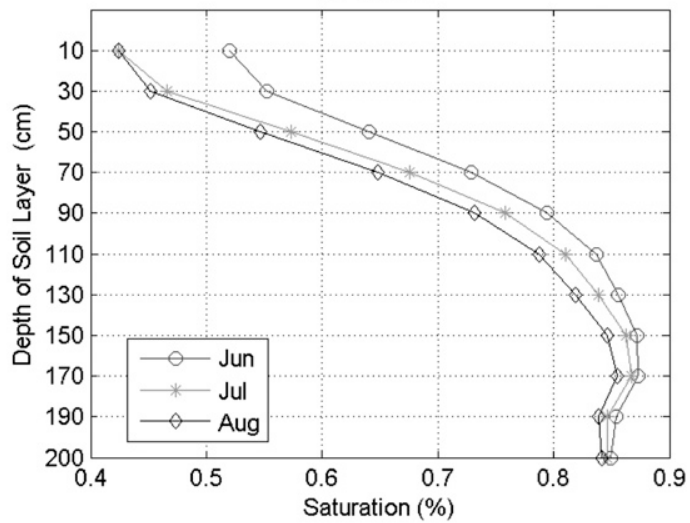

(d) Winter

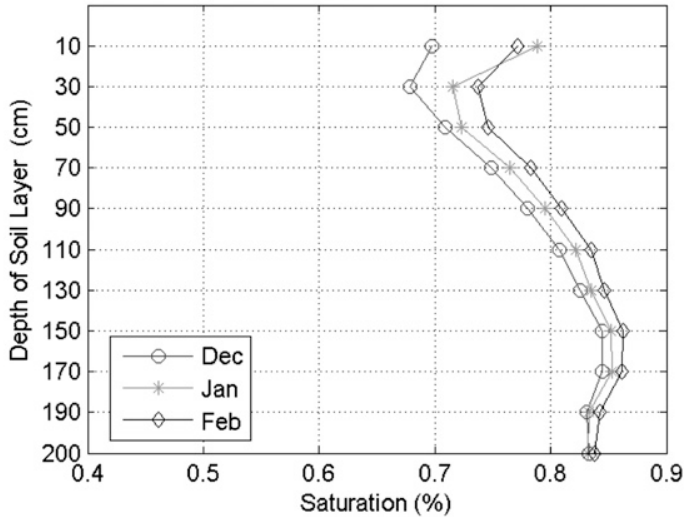

FIG. 8. The 16-station average long-term (1984-2002) vertical profile of soil relative saturation in Illinois on a monthly basis; (a) spring (MAM), (b) summer (JJA), (c) autumn (SON), winter (DJF). 


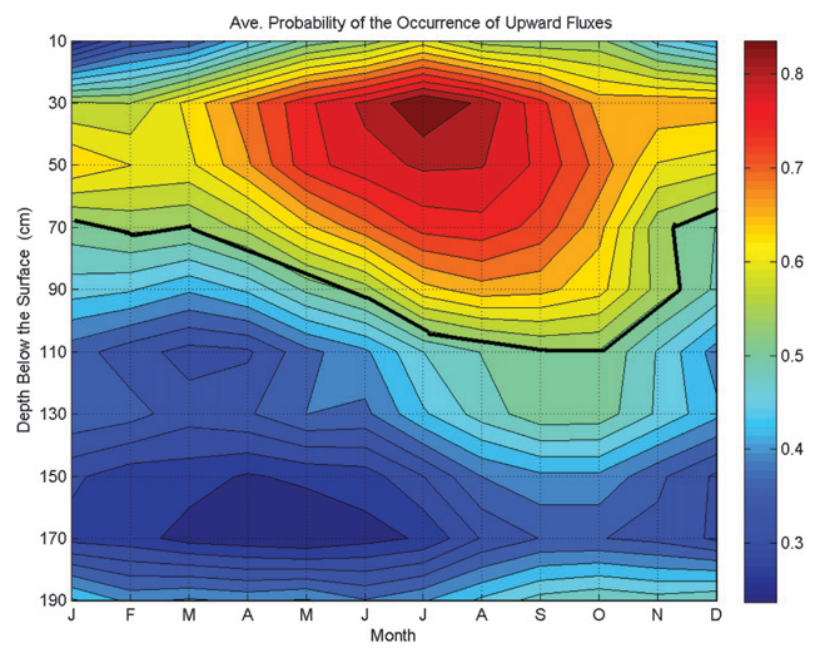

FIG. 9. Contour plot of the 1984-2002 average seasonal cycle of the probability for the upward water flux occurrence at the 11 soil layers from 0 to $2 \mathrm{~m}$ below the surface. The zero-flux plane $(\sim 50 \%$ probability for the occurrence of upward fluxes) is marked by a solid black line.

water flux supplied from the deeper soil layers to replenish the root-zone soil moisture in summer. On the other hand, the maximum downward flux (drainage) occurs in the deep layer of about $150-170 \mathrm{~cm}$ when the water table depth is shallowest. Moreover, the evolution of the zero-flux plane (Stephens 1996; Scanlon et al. 2002), which separates the upward movement of soil water to evapotranspiration from the downward movement to the water table, can be estimated by approximately $50 \%$ probability contours in Fig. 9 . The zero-flux plane is found to be in the intermediate layers of about $70-110 \mathrm{~cm}$, marked by a black line in Fig. 9. It shows a seasonal downward propagation from spring to fall. Since soil moisture below 1-m depth is nearly constant throughout the year (Fig. 8), the direction and magnitude of the moisture fluxes across the zero-flux plane is approximately equal to the fluxes across the water table, which is in average $3.5 \mathrm{~m}$ below the surface in Illinois (Yeh and Famiglietti 2008, their Fig. 2). Therefore, it can be inferred that the upward fluxes across the zeroflux plane for supplying deeper root-zone soil moisture during summer are originated from the water source beneath the 2-m depth of the soil profile. As shown in Fig. 9, the zero-flux plane moves downward from 70 (May) to $110 \mathrm{~cm}$ (August), reflecting the water supply from progressively lower depths in response to high summer evapotranspiration demand.

In fact, the zero-flux plane can provide an estimate of groundwater recharge based on the premise that recharge is equal to changes in soil-moisture storage below the zero-flux plane (Scanlon et al. 2002). However, it requires capillary potential data to locate the zero-flux plane and soil water content data to measure changes in storage, hence its application has been limited. In this study, similar difficulty due to the lack of capillary potential data is encountered, thus we have to resort to estimating the direction of soil water fluxes rather than the magnitude of fluxes. Because of the uncertainty in the water-retention characteristics, the detailed pattern shown in Fig. 9 should be taken merely as a first-order approximation. However, we have attempted to vary the values of $\psi_{S}$ and $B$ within a reasonable range for silt loam soils as well as use alternative water retention characteristics, and the results show little sensitivity to the pattern in Fig. 9. Considering that the motivation here is to quantify the frequency of upward fluxes rather than to determine its magnitude, the analyses and discussion offered in this section are believed to have justified the occurrence and provided the observed evidence of groundwater evaporation.

Figure 10 presents a similar plot to Fig. 9 but for the 1984-2002 yearly average probability for the occurrence of upward fluxes. The hydroclimatology in Illinois during the study period 1984-2003 was marked by the occurrence of several extreme summer anomalies including the 1988 summer drought and the 1993 summer flood. As shown, both anomalous years have left a clear signature on the soil water flux patterns. The drought that occurred in 1988 manifested itself with the highest possibility of upward flux occurrence at the root zone $(\sim 30-50 \mathrm{~cm})$. In contrast, the flood in 1993 was marked by the dominant downward drainage flux $(\sim 80 \%$ of probability) occurring at the shallowest depth of about $110 \mathrm{~cm}$ during the $20-y r$ period.

Supporting the observed interactions between deep soil moisture and groundwater, Fig. 11 plots the correlation coefficient between the relative soil saturation in 11 layers and the corresponding precipitation, runoff, and groundwater depth. A high correlation $(R=\sim 0.9)$ is found between relative saturation and groundwater depth at depths of about $0.7-1.3 \mathrm{~m}$, which approximately coincide with the location of the zero-flux plane in Fig. 9. Since the seasonal evolution of the zero-flux plane mimics the annual cycle of groundwater depth, it implies that the 1-m depth is approximately where the intensive water exchange between soil moisture and groundwater takes place. Also shown in this figure is the relatively low correlation between soil saturation and precipitation, which reflects the energy-limited characteristics of the hydroclimatology in Illinois (Yeh et al. 1998). Since precipitation shows no clear seasonal pattern (Fig. 2), the strong annual cycle of incoming solar radiation (Eltahir and Yeh 1999, their Fig. 5) leaves its signature on the soil saturation through evapotranspiration. 


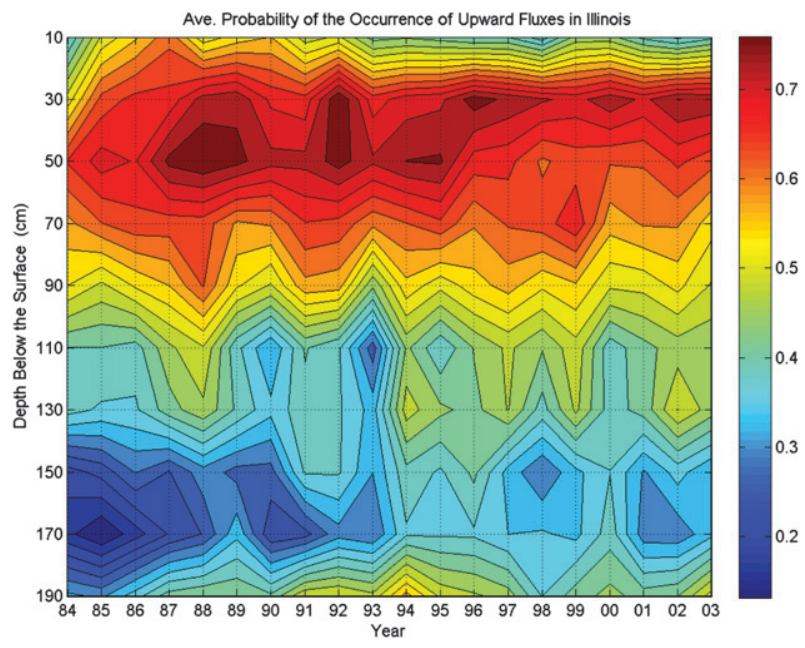

FIG. 10. Same as Fig. 9 but for interannual variability of yearly average probability of upward water flux occurrence.

\section{Summary}

The process of water supply from shallow unconfined aquifers to root-zone soil moisture, and the subsequent use for plant transpiration (i.e., groundwater evapotranspiration), has not been fully recognized in hydrologic literature and the land surface modeling community. Very few regional-scale field studies on groundwater evapotranspiration have been reported in literature. This mechanism is significant when the depth to the water table is comparable to the rooting depth of plants. In this study, we have demonstrated the role of groundwater evapotranspiration at a regional scale by using a 19-yr (1984-2002) observed hydrological dataset in Illinois including soil moisture, water table depth, and streamflow. Regional groundwater recharge is estimated using soil water balance computation. It is found that groundwater recharge exhibits two peaks and one trough. Both peaks occur outside of the growing season. The first peak is February-March and corresponds to the maximum soil moisture content and groundwater levels, while the second peak in November occurs when the precipitation minus evaporation is at maximum. The 19-yr (1984-2002) average groundwater recharge is estimated to be $244 \mathrm{~mm}$ $\mathrm{yr}^{-1}(25 \%$ of precipitation), with the uncertainty ranging from 202 to $278 \mathrm{~mm} \mathrm{yr}^{-1}$.

Negative groundwater recharge (groundwater evaporation) is found to occur during the period of JulySeptember, indicating an upward capillary flux from the shallow aquifer to maintain the high summer evapotranspiration rate. Groundwater evaporation is equal to $\sim 10 \%$ of total evapotranspiration of the same period, consistent with the findings from earlier modeling (Gutowski et al. 2002; Cohen et al. 2006) and field

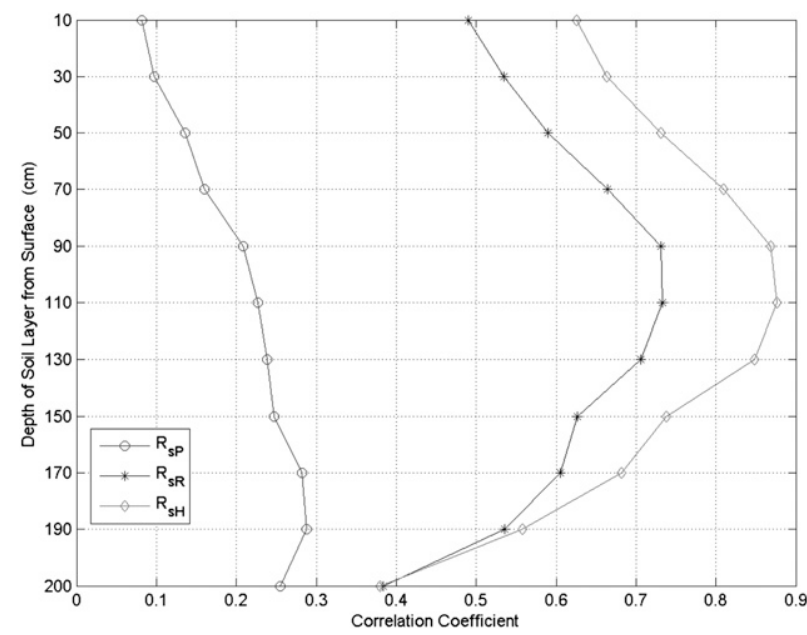

FIG. 11. The correlation coefficient between the 1984-2002 monthly relative saturation in 11 soil layers and the corresponding monthly precipitation $\left(R_{s P}\right)$, streamflow $\left(R_{s R}\right)$, and groundwater depth $\left(R_{s H}\right)$.

(Tschinkel 1963; Daniel 1976; Zecharias and Brutsaert 1988) studies. Analysis of the pattern of relative soil saturation at 11 depths supports the dominance of groundwater evaporation across the water table in dry periods and especially during the drought years like 1988. The zero-flux plane separating the recharge zone from the evapotranspiration zone is estimated to propagate downward from approximately 70 to $110-\mathrm{cm}$ depth during summer, reflecting the water supply from progressively lower layers for high evapotranspiration.

Although the magnitude of groundwater evaporation is relatively small, it may have significant implication for land surface parameterizations used in climate modeling. Because much of the transfer of water from the soil into the atmosphere is through transpiration, the physical mechanism of groundwater evapotranspiration needs to be realistically represented. Despite its small magnitude, neglecting regional groundwater evaporation in shallow groundwater areas would result in underestimated root-zone soil moisture and hence evapotranspiration by as much as $20 \%$ in the dry summer seasons (Fig. 2). Finally, it should be emphasized that for the arid or semiarid regions where the water table is deep, groundwater evaporation can be observed only for the riparian vegetation community. In riparian corridors, however, vegetation species partially or completely rely on groundwater as the only water source for survival (Snyder and Williams 2000; Tabacchi et al. 2000; Lamontagne et al. 2005), thus the representation of groundwater evaporation is even more critical for the plant transpiration simulations (Baird and Maddock 2005) 
Acknowledgments. We gratefully acknowledge the support of this research, which was funded by NOAA Grant NA05OAR4310013.

\section{REFERENCES}

Allison, G. B., and C. J. Barnes, 1985: Estimation of evaporation from the normally 'dry' Lake Frome in South Australia. $J$. Hydrol., 78, 229-242.

Amenu, G. G., and P. Kumar, 2008: A model for hydraulic redistribution incorporating coupled soil-root moisture transport. Hydrol. Earth Syst. Sci., 12, 55-74.

Arnold, J. G., R. S. Muttiah, R. Srinivasan, and P. M. Allen, 2000: Regional estimation of base flow and groundwater recharge in the Upper Mississippi River basin. J. Hydrol., 227, 21-40.

Baird, K. J., and T. Maddock III, 2005: Simulating riparian evapotranspiration: A new methodology and application for groundwater models. J. Hydrol., 312, 176-190.

Changnon, S. A., F. A. Huff, and C.-F. Hsu, 1988: Relations between precipitation and shallow groundwater in Illinois. $J$. Climate, 1, 1239-1250.

Clapp, R. B., and G. M. Hornberger, 1978: Empirical equations for some soil hydraulic properties. Water Resour. Res., 14, 601-604.

Cohen, D., and Coauthors, 2006: Groundwater-supported evapotranspiration within glaciated watersheds and under conditions of climate change. J. Hydrol., 320, 484-500.

Dahm, C. N., M. B. Baker, D. I. Moore, and J. R. Thibault, 2003: Coupled biogeochemical and hydrological responses of streams and rivers to drought. Freshwater Biol., 48, 1219-1231.

Daniel, J. F., 1976: Estimating groundwater evapotranspiration from streamflow records. Water Resour. Res., 12, 360-364.

Eltahir, E. A. B., and P. J.-F. Yeh, 1999: On the asymmetric response of aquifer water level to floods and droughts in Illinois. Water Resour. Res., 35, 1199-1217.

Famiglietti, J. S., and E. F. Wood, 1994: Multiscale modeling of spatially variable water and energy balance processes. Water Resour. Res., 30, 3061-3078.

Fan, Y., G. Miguez-Macho, C. Weaver, R. Walko, and A. Robock, 2007: Incorporating water table dynamics in climate modeling: 1. Water table observations and the equilibrium water table simulations. J. Geophys. Res., 112, D10125, doi:10.1029/ 2006JD008111.

Gardner, W. R., 1958: Some steady-state solutions of the unsaturated moisture flow equation with application to evaporation from a water table. Soil Sci., 85, 228-232.

_ from soil columns in the presence of a water table. Soil Sci., 85, 244-249.

Gutowski, W. J., Jr., C. J. Vörösmarty, M. Person, Z. Ötles, B. Fekete, and J. York, 2002: A coupled land-atmosphere simulation program (CLASP): Calibration and validation. J. Geophys. Res., 107, 4283, doi:10.1029/2001JD000392.

Hollinger, S. E., and S. A. Isard, 1994: A soil moisture climatology of Illinois. J. Climate, 7, 822-833.

Kleidon, A., and M. Heimann, 2000: Assessing the role of deep rooted vegetation in the climate system with model simulations: Mechanism, comparison to observations and implication for Amazonian deforestation. Climate Dyn., 16, 183-199.

Koster, R. D., M. J. Suarez, A. Ducharne, M. Stieglitz, and P. Kumar, 2000: A catchment-based approach to modeling land surface processes in a general circulation model: 1 . Model structure. J. Geophys. Res., 105 (D20), 24 809-24 822.
Lamontagne, S., P. G. Cook, A. O'Grady, and D. Eamus, 2005: Groundwater use by vegetation in a tropical savanna riparian zone (Daly River, Australia). J. Hydrol., 310, 280-293.

Levine, J. B., and G. D. Salvucci, 1999: Equilibrium analysis of groundwater-vadose zone interactions and the resulting spatial distribution of hydrologic fluxes across a Canadian prairie. Water Resour. Res., 35, 1369-1384.

Liang, X., Z. Xie, and M. Huang, 2003: A new parameterization for surface and groundwater interactions and its impact on water budgets with the variable infiltration capacity (VIC) land surface model. J. Geophys. Res., 108, 8613, doi:10.1029/ 2002JD003090.

Malek, E., G. E. Bingham, and G. D. McCurdy, 1990: Evapotranspiration from the margin and moist playa of a closed desert valley. J. Hydrol., 120, 15-34.

Maraux, F., and F. Lafolie, 1998: Modeling soil water balance of a maize-sorghum sequence. Soil Sci. Soc. Amer. J., 62, 75-82.

Mau, D. P., and T. C. Winter, 1997: Estimating ground-water recharge from streamflow hydrographs for a small mountain watershed in a temperate humid climate, New Hampshire, USA. Ground Water, 35, 291-304.

Maxwell, R. M., and N. L. Miller, 2005: Development of a coupled land surface and groundwater model. J. Hydrometeor., 6, 233247.

Miller, S. A., and P. S. Eagleson, 1982: Interaction of the saturated and unsaturated soil zones. MIT, Parsons Laboratory Rep. No. 284, 289 pp.

National Research Council, 2004: Groundwater Fluxes across Interfaces. The National Academic Press, 85 pp.

Nepstad, D. C., and Coauthors, 1994: The role of deep roots in the hydrological and carbon cycles of Amazonian forests and pastures. Nature, 372, 666-669.

Nichols, W. D., 1993: Estimating annual groundwater discharge by greasewood in areas of shallow groundwater in the northern Great Basin using an energy-combination model. Water Resour. Res., 29, 2771-2778.

- 1994: Groundwater discharge by phreatophyte shrubs in the Great Basin as related to depth to groundwater. Water Resour. Res., 30, 3265-3274.

Niu, G.-Y., Z.-L. Yang, R. E. Dickinson, L. E. Gulden, and H. Su, 2007: Development of a simple groundwater model for use in climate models and evaluation with gravity recovery and climate experiment data. J. Geophys. Res., 112, D07103, doi:10.1029/ 2006JD007522.

Oliveira, R. S., T. E. Dawson, S. S. O. Burgess, and D. C. Nepstad, 2005: Hydraulic redistribution in three Amazonian trees. Oecologia, 145, 354-363.

Remson, I., and G. S. Fox, 1955: Capillary losses from ground water. Eos, Trans. Amer. Geophys. Union, 36, 304-310.

Rodell, M., and J. S. Famiglietti, 2001: An analysis of terrestrial water storage variations in Illinois with implications for Gravity Recovery and Climate Experiment (GRACE). Water Resour. Res., 37, 1327-1339.

Saleska, S. R., K. Didan, A. R. Huete, and H. R. da Rocha, 2007: Amazon forests green-up during 2005 drought. Science, 318, 5850, doi:10.1126/science. 1146663 .

Scanlon, B. R., R. W. Healy, and P. G. Cook, 2002: Choosing appropriate techniques for quantifying groundwater recharge. Hydrogeol. J., 10, 18-39.

Schmidhalter, U., H. S. Salem, and J. J. Oertli, 1994: Measuring and modeling root water uptake based on ${ }^{36}$ chloride discrimination in a silt loam soil affected by groundwater. Soil Sci., 158, 97-105. 
Scott, R. L., T. E. Huxman, D. G. Williams, and D. C. Goodrich, 2006: Ecohydrological impacts of woody-plant encroachment: Seasonal patterns of water and carbon dioxide exchange within a semiarid riparian environment. Global Change Biol., 12, 311-324.

Shaw, C., and A. Smith, 1927: Maximum height of capillary rise starting with a soil at capillary saturation. Hilgardia, 2, 399-409.

Snyder, K. A., and D. G. Williams, 2000: Water sources used by riparian trees varies among stream types on the San Pedro River, Arizona. Agric. For. Meteor., 105, 227-240.

Sophocleous, M., and C. A. Perry, 1985: Experimental studies in natural groundwater recharge dynamics: The analysis of observed recharge events. J. Hydrol., 81, 297-332.

Steinwand, A. L., R. F. Harrington, and D. Or, 2006: Water balance for Great Basin phreatophytes derived from eddy covariance, soil water, and water table measurements. J. Hydrol., 329, 595-605.

Stephens, D. B., 1996: Vadose Zone Hydrology. Lewis Publishers, $339 \mathrm{pp}$.

Stieglitz, M., D. Rind, J. Famiglietti, and C. Rosenzweig, 1997: An efficient approach to modeling the topographic control of surface hydrology for regional and global climate modeling. $J$. Climate, 10, 118-137.

Swenson, S. C., P. J.-F. Yeh, J. Wahr, and J. S. Famiglietti, 2006: A comparison of terrestrial water storage variations from GRACE with in situ measurements from Illinois. Geophys. Res. Lett., 33, L16401, doi:10.1029/2006GL026962.

Tabacchi, E., L. Lambs, H. Guilloy, A. M. P. Tabacchi, E. Muller, and H. Decamps, 2000: Impacts of riparian vegetation on hydrological processes. Hydrol. Processes, 14, 2959-2976.

Tschinkel, H. M., 1963: Short-term fluctuation in streamflow as related to evaporation and transpiration. J. Geophys. Res., 68 , 6459-6469.
Tyler, S. W., S. Kranz, M. B. Parlange, J. Albertson, G. G. Katul, G. F. Cochran, B. A. Lyles, and G. Holder, 1997: Estimation of groundwater evaporation and salt flux from Owens Lake, California, USA. J. Hydrol., 200, 110-135.

Ullman, W. J., 1985: Evaporation rate from a salt pan: Estimates derived from chemical profiles in near-surface groundwater. $J$. Hydrol., 79, 365-373.

Willis, W. O., 1960: Evaporation from layered soils in the presence of a water table. Soil Sci. Soc. Amer. J., 24, 239-242.

Yeh, P. J.-F., and E. A. B. Eltahir, 2005a: Representation of water table dynamics in a land surface scheme. Part I: Model development. J. Climate, 18, 1861-1880.

$\longrightarrow$, and - 2005b: Representation of water table dynamics in a land surface scheme. Part II: Subgrid variability. J. Climate, 18, 1881-1901.

— , and J. Famiglietti, 2008: Regional terrestrial water storage change and evapotranspiration from terrestrial and atmospheric water balance computations. J. Geophys. Res., 113, D09108, doi:10.1029/2007JD009045.

_ M. Irizarry, and E. A. B. Eltahir, 1998: Hydroclimatology of Illinois: A comparison of monthly evaporation estimates based on atmospheric water balance and soil water balance. $J$. Geophys. Res., 103 (D16), 19 823-19 837.

— J J. Famiglietti, S. C. Swenson, and M. Rodell, 2006: Remote sensing of groundwater storage changes in Illinois using the Gravity Recovery and Climate Experiment (GRACE). Water Resour. Res., 42, W12203, doi:10.1029/2006WR005374.

York, J. P., M. Person, W. J. Gutowski, and T. C. Winter, 2002: Putting aquifers into atmospheric simulation models: An example from the Mill Creek Watershed, northeastern Kansas. Adv. Water Resour., 25, 221-238.

Zecharias, Y. B., and W. Brutsaert, 1988: Recession characteristics of groundwater outflow and baseflow from mountainous watersheds. Water Resour. Res., 24, 1651-1658. 